\title{
Evaluation of the Physical Activity Level of Elderly Women in the Canton of Sarajevo in Bosnia and Herzegovina
}

\author{
Izet Bajramovic ${ }^{1}$, Dusko Bjelica², Munir Talovic ${ }^{1}$, Haris Alic ${ }^{1}$, Slavenko Likic ${ }^{1}$ \\ 'University of Sarajevo, Faculty for Sport and Physical Education, Sarajevo, Bosnia and Herzegovina, ${ }^{2}$ University of Montenegro, Faculty for Sport \\ and Physical Education, Niksic, Montenegro
}

\begin{abstract}
The aim of this study was to determine the level of physical activity of elderly women living in the Canton of Sarajevo in Bosnia and Herzegovina. The sample consisted of 115 subjects, divided in two sub-sample: first group aged 50-59 (54.87 \pm 2.59$), \mathrm{N}=75$; and second group aged 60-69 (64.52 \pm 2.80$), \mathrm{N}=40$. Data collection was obtained using a long version of the International Physical Activity Questionnaires (IPAQ). After the results analysis, a high overall level of physical activity of the treated sample of elderly women was determined. The first group of elderly women (age 50-59) achieved the total work MET 13990.56 \pm 11012.0 ; the second group of elderly women (age 60-69) achieved the total work MET $9921.02 \pm 7861.13$. Determined exceptionally heavy physical activity (MET) was the most dominant mode of energy consumption in the case of both elderly women groups, was not expected. The first group was more physically active compared to the second group of elderly women $(p<0.05)$. This research has confirmed that physical activity decreases with age. Promoting physical activity to improve the quality of life of elderly people should be a priority task of health policy of all local communities. It is important to provide appropriate ways of information about the health status of elderly people in order to determine priorities, and accordingly plan appropriate programs of physical activity.
\end{abstract}

Key words: Metabolic equivalent of MET, Older age, Health, Local community

\section{Uvod}

Biološkim procesom starenja se snižava nivo tjelesnih funkcija čovjeka. Biološke promjene se ogledaju u smanjenoj radnoj sposobnosti, bržem zamaranju, te sporijem oporavku nakon fizičkih aktivnosti. Starenjem se smanjuje tolerancija na glukozu i osjetljivost na inzulin, što se može poboljšati primjenom redovne fizičke aktivnosti (Bjelica, 2010). Visoki nivo inzulina, kao i nizak nivo mišićne snage i tjelesne mase predstavljaju faktore koji zajedno najviše doprinose riziku razvoja metaboličkog sindroma (Atlantis, Martin, Haren, Taylor, \& Wittert, 2009).

Poznato je da fizička aktivnost (FA) podrazumijeva bilo kakav tjelesni pokret koji je proizveden radom skeletnih mišića, te utiče na energetsku potrošnju. Fizička aktivnost se može, u svakodnevnom životu, kategorizovati u različitim područjima zanimanja, slobodnog vremena, sporta, kućnih poslova ili drugih aktivnosti (Caspersen, Powell, \& Christenson, 1985). Odgovarajućim fizičkim aktivnostima ne može se zaustaviti proces starenja, ali se može usporiti opadanje i održati visok nivo bioloških funkcija čovjeka. Naime, redovnim sudjelovanjem (dnevno 30 minuta tokom većine dana u sedmici) $u$ aktivnostima umjerenog intenziteta (kao što su hodanje, penjanje uz stepenice, vožnja bicikla ili vrtlarstvo) postupno se akumulira i povećava dnevna energetska potrošnja, te također održava mišićna snaga. Ovakve fizičke aktivnosti ne moraju biti izrazito teške kako bi se poboljšala fizička kondicija, te ih takođe treba poticati u slučaju starijih osoba (DiPietro, 2001).

Nivo energetske potrošnje tokom fizičkih aktivnosti mo-

Correspondence:

Montenegro S.Likić

Gport University of Sarajevo, Faculty for Sport and Physical Education, Patriotske lige 41, 71000 Sarajevo, Bosnia and Herzegovina E-mail: slikic@fasto.unsa.ba 
že se odrediti pomoću metaboličkog ekvivalenta (MET Metabolic Equivalent of Task), a koji se pri određenoj fizičkoj aktivnosti izračunava na osnovu potrošnje kiseonika po kilogramu tjelesne mase. Jedan MET odgovara nivou metabolizma u stanju mirovanju i iznosi $3,5 \mathrm{ml} \mathrm{O} / \mathrm{kg} / \mathrm{min}$. Cilj ovog istraživanja je utvrditi nivo fizičke aktivnosti starijih žena koje su nastanjene u Kantonu Sarajevo, u Bosni i Hercegovini.

Veći nivo ukupne FA je značajno povezan sa manjim zdravstvenim rizicima, a pozitivni efekti mogu nastati i pri nižim nivoima FA (do 3000-4000 MET min/sedmično). Na primjer, osobe sa ukupnim nivoom FA od $600 \mathrm{MET}$ min/sedmično, što je ujedno minimalni preporučeni nivo FA, imaju $2 \%$ manji rizik od dijabetesa u odnosu na fizički neaktivne osobe. Povećanjem FA sa 600 na 3600 MET min/sedmično smanjuje se rizik za dodatnih 19\%. Uspoređujući nedovoljno aktivne osobe (ukupna aktivnost $<600 \mathrm{MET} \mathrm{min} /$ sedmično) sa visoko aktivnim osobama (ukupna aktivnost $\geq 8000 \mathrm{MET} \mathrm{min} / \mathrm{sed}$ mično), ustanovljeno je smanjenje različitih zdravstvenih rizika u slučaju osoba koje pripadaju visoko aktivnoj kategoriji. Ovi zdravstveni rizici su se odnosili na smanjenje rizika od raka dojke za $14 \%$; raka debelog crijeva za $21 \%$; dijabetesa za $28 \%$; ishemijsku bolest srca za 25\%; i ishemijski moždani udar za 26\% (Kyu, Bachman, i sar. 2016).

\section{Metod}

Uzorak ispitanika su predstavljale osobe ženskog pola ( $\mathrm{N}=115)$, nastanjene u Kantonu Sarajevo u Bosni i Hercegovini. Uzorak je prema hronološkoj starosti raspodijeljen na dva sub-uzorka. Prvu grupu su činile žene u starosti 50-59 godina, od kojih je $70,67 \%$ bilo nastanjeno na području grada, dok je ostatak od 29,33\% bio nastanjen u ostalim prigradskim naseljima ili selima. Drugu grupu su činile žene u starosti 60-69 godina, od kojih je $85 \%$ bilo nastanjeno na području grada, dok je ostatak od $15 \%$ bio nastanjen u ostalim prigradskim naseljima ili selima. U svrhu ovog istraživanja, ispitanici su dobrovoljno ispunili Međunarodnog upitnik samo-procjene fizičke aktivnosti (IPAQ - International Physical Activity Questionnaires) odnosno njegovo dugu verziju (Craig, Marshall, Sjostrom, Bauman, Booth, Ainsworth, Pratt, Ekelund, Yugve, Sallis, \& Oja 2003). Ovim upitnikom su obuhvaćena četiri područja djelovanja: fizička aktivnost na poslu; fizička aktivnost u prevozu; kućni poslovi, održavanje kuće i briga za porodicu; te rekreacija, sport i fizička aktivnost u slobodnom vremenu.

Anketiranje je sprovedeno tokom oktobra i novembra 2017. godine. Anketni upitnici su u slučaju 21 osobe, a koje su prijavile mjesto stanovanja izvan Kantona Sarajevo ili neodgovarajuću godinu rođenja u odnosu na kriterij 50-69 godina starosti, izostavljeni iz analize.

Tabela 1. Osnovne karakteristike uzorka ispitanica

\begin{tabular}{ccc}
\hline Starosna dob & AS \pm SD & Procent (\%) \\
\hline $50-59$ & $54,87 \pm 2,59$ & 65,22 \\
$60-69$ & $64,52 \pm 2,80$ & 43,78 \\
\hline
\end{tabular}

Rezultati su izraženi u MET min/sedmično. MET rezultat se posebno izračunava za svaku vrstu aktivnosti (Ainsworth, Haskell, Whitt i sar., 2000). Različiti nivoi FA su klasifikovani u odnosu na stopu energetske potrošnje kao: teška FA, umjere- na FA i hodanje. Za analizu IPAQ podataka koriste se sljedeće vrijednosti, odnosno formule kojima se izračunava nivo FA za svako područje (tabela 2). Također, zbirom trajanja FA u svim tretiranim područjima se dobiva ukupni FA.

Tabela 2. Određivanje nivoa energetske potrošnje pri fizičkim aktivnosti

\begin{tabular}{ll}
\hline FA & \multicolumn{1}{c}{ Formula } \\
\hline Hodanje $=3.3$ MET & $3.3=$ vrijeme FA u minutama * broja dana u sedmici \\
Umjerena FA $=4.0$ MET & $4.0=$ vrijeme FA u minutama * broja dana u sedmici \\
Teška FA = 8,0 MET & $8.0=$ vrijeme FA u minutama * broja dana u sedmici \\
Ukupna FA MET-min u sedmici & Hodanje + umjerena FA + teška FA \\
\hline
\end{tabular}

Podaci su obrađeni korištenjem statističkog paketa (SPSS Inc., Chicago, IL, USA). Izračunata je aritmetička sredina (AS) i standardna devijacija (SD) metaboličkog ekvivalenta (MET - Metabolic Equivalent Task), posebno za svako područje FA. Razlika u nivou FA između dvije grupe ispitanica je utvrđena primjenom t-testa za nezavisne uzorke, na postavljenom nivou statističke značajnosti od $\mathrm{p}<0.05$.

\section{Rezultati}

Pregledom deskriptivnih parametara varijabli za procjenu energetske potrošnje pri fizičkim aktivnostima, primjetne su veće vrijednosti aritmetičkih sredina u svim tretiranim varijablama, u slučaju grupe žena u starosti 50-59 godina (tabela 3). Uvidom u rezultate standardnih devijacija, evidentna je veća varijabilnost svih rezultata. Rezultati Levenovog testa (Levene's Test for Equality of Variances), gdje je p-vrijednost $>0.05$ ukazuju da je pretpostavka o jednakim varijacijama (Equal variances assumed) ispunjena kod varijabli ukupne aktivnosti u prevozu (.010); ukupne aktivnosti u dvorištu i kući (.604); ukupne aktivnosti u slobodnom vremenu (.856); ukupne ak- tivnosti umjerenog intenziteta (.059); i ukupne izrazito naporne aktivnosti (.095). U slučaju varijabli ukupne aktivnosti na poslu (.005); ukupno hodanje (.034); i ukupan rad (.037), gdje je p-vrijednost $<0.05$, ova pretpostavka nije tačna (Equal variances not assumed), te su rezultati morali biti korigovani. U konačnici, može se zaključiti da ukupna fizička aktivnosti na poslu, ukupno hodanje, kao i ukupni rad (.037), statistički značajno razlikuje dvije grupe žena različite starosne dobi $(\mathrm{p}<0.05)$.

Uvidom u dobivene rezultate istraživanja, može se konstatovati visoki nivo fizičkih aktivnosti starijih ženskih osoba nastanjenih u Kantonu Sarajevo. Ispitanice prve grupe žena (starosti 50-59 godina) su dvostruko fizički aktivnije u području aktivnosti na poslu (MET) u odnosu na grupu starijih žena (starost 60-69 godina). Prva grupa starijih žena ostvaruje najveću energetsku potrošnju u području fizičkih aktivnosti u prevozu (MET), za razliku od druge grupe starijih žena koje ostvaruju najveći nivo aktivnosti u dvorištu i kući (MET) u odnosu na preostala područja. Iako je potrošnja energije na zadovoljavajućem nivou u slučaju obje grupe ispitanica, ova 
Tabela 3. Fizička aktivnost tretiranih grupa žena starije dobi u proteklih sedam dana

\begin{tabular}{lccc}
\hline & $\begin{array}{c}\mathbf{5 0 - 5 9} \text { (N=75) } \\
\text { Mean } \pm \text { S.D. }\end{array}$ & $\begin{array}{c}\mathbf{6 0 - 6 9} \text { (N=40) } \\
\text { Mean } \pm \text { S.D. }\end{array}$ & $\begin{array}{c}\text { Sig. } \\
\text { (2-tailed) }\end{array}$ \\
\hline Ukupne aktivnosti na poslu (MET) & $4126.46 \pm 6623.93$ & $1962.02 \pm 4171.77$ & .034 \\
Ukupne aktivnosti u prevozu (MET) & $4259.36 \pm 5573.49$ & $2673.75 \pm 2798.23$ & .094 \\
Ukupne aktivnosti u dvorištu i kući (MET) & $2934.61 \pm 3898.60$ & $2766.95 \pm 3606.29$ & .822 \\
Ukupne aktivnosti u slobodnom vremenu (MET) & $2391.12 \pm 3702.03$ & $2151.55 \pm 3927.99$ & .747 \\
Ukupno hodanje (MET) & $3817.44 \pm 3964.93$ & $2489.02 \pm 2695.04$ & .036 \\
Ukupne aktivnosti umjerenog intenziteta (MET) & $2625.60 \pm 3177.71$ & $1748.00 \pm 2558.36$ & .135 \\
Ukupne izrazito naporne aktivnosti (MET) & $7120.32 \pm 6526.89$ & $5468.00 \pm 5346.70$ & .172 \\
Ukupni rad (MET) & $13990.56 \pm 11012.0$ & $9921.02 \pm 7861.13$ & .024 \\
\hline
\end{tabular}

Legenda: Mean - Aritmetička sredina; S.D. - Standardna devijacija; Sig. - Statistička značajnost

potrošnja je najniža kroz fizičku aktivnost u slobodnom vremenu (MET), u uporedbi sa preostalim područjima.

Upoređujući dobivene rezultate sa istraživanjem koje je realizovano na uzorku žena identične starosti na području gradova Podgorice i Bara u Crnoj Gori (Knežević, 2018), može se konstatovati da su žene na području Kantona Sarajevo $(\mathrm{BiH})$ ostvarile veći ukupni fizički rad (MET). Ova razlika je manje izražena u slučaju starosne grupe 60-69 godina. Najveća razlika je prisutna u okviru fizičke aktivnosti u prevozu, gdje su starije žene iz Kantona Sarajevo ostvarile veći nivo aktivnosti u slučaju obje starosne grupe. Ova razlika je takođe prisutna u odnosu na starije muške osobe sa područja Bara i okoline (Kovačević, 2018), kao i Nikšića i okoline (Mitrović, 2018), u Crnoj Gori. Najveći nivo energetske potrošnje su obje grupe starijih žena ostvarile kroz izrazito naporne fizičke aktivnosti.

\section{Diskusija}

Evidentno je da procesom biološkog starenja, fizičke aktivnosti opadaju u slučaju starijih žena nastanjenih u Kantonu Sarajevo (BiH). Prema Popoviću, Bjelici, Vukotićevoj \& Mašanoviću (2018), prevalencija fizičke neaktivnosti među starijim crnogorskim ženama je relativno visoka, te se povećava u skladu sa starosnom dobi. Isti slučaj je takođe konstatovan na starijoj muškoj populaciji (Mašanović, Vukotić, Bjelica, \& Popović, 2018). Kritični prag koji se odnosi na gubitak snage, upravo zavisi od životne dobi (Zatsiorsky \& Kraemer, 2009). Nivo potencijala snage značajno opada tokom šeste decenije (15\%), dok je najveći tokom sedme decenije života (30\%). Sharkey \& Gaskill (2008) navode da aerobne sposobnosti opadaju za $8-10 \%$ tokom svake decenije života, međutim ova tendencija je manje izražena u slučaju umjereno aktivnih osoba, te iznosi 4-5\%. Kod izrazito aktivnih osoba tendencija opadanja aerobnih sposobnosti tokom svake decenije života može biti veoma mala, te iznosi $2 \%$ ili manje.

Niži stepen zaposlenosti druge grupe žena (starosti 60-69 godina) u odnosu na prvu grupu žena (starosti 50-59 godina) može posljedično imati dodatne fizičke aktivnosti u dvorištu i kući, što je područje u kojem je utvrđena najveća stopa energetske potrošnje.

Korištenje slobodnog vremena, upražnjavajući pritom zdravu fizičku aktivnost s ciljem upravljanja vlastitim zdravljem, treba da postane prioritet u životu starijih osoba. Istraživanja potvrđuju da starije osobe koje su ostale fizički aktivne imaju veći nivo snage nego neaktivne osobe, što takođe upućuje na povezanost fizičke aktivnosti i psihomotornih funkcija starijih osoba (Bjelica, \& Krivokapić, 2010). Uspostavljanje i održavanje visokog nivoa fizičke aktivnosti, koja uzrokuje dodatnu energetsku potrošnju, trebalo bi da po- stane prioritet u životu starijih ljudi. Vrsta aktivnosti je manje važna od količine, frekvencije i intenziteta aktivnosti (Taylor, 2014). Ipak, pritom treba svesti na minimum sve potencijalne rizike od fizičkog povređivanja. Fizičke aktivnosti treba u početku usmjeriti na usvajanje i održavanje najmanje $150 \mathrm{mi}-$ nuta sedmično, a potom postepeno povećavati do preporučenog nivoa od 60 minuta dnevno (Jakičić, Marcus, Gallagher, Napolitano, \& Lang, 2003). Naime, tjelesna funkcionalnost i nezavisnost su važni faktori za održavanje kvalitete života starijih osoba.

Izrazito teške fizičke aktivnosti (MET), koje su se pokazale kao najdominantniji način energetske potrošnje u slučaju obje grupe ispitanica, nisu bile očekivane. Prema pojedinim istraživanjima, starije osobe se teže odlučuju za teške fizičke aktivnosti (DiPietro, 2001). Milanović i sar. (2012) navode da se teške aktivnosti definišu kao aktivnosti u kojima ispitanici dišu mnogo dublje nego obično. Ovakve aktivnosti mogu biti na primjer dizanje teških stvari, kopanje, teški građevinski radovi ili penjanje uz stepenice. S druge strane, umjerene fizičke aktivnosti su one koje podrazumijevaju nešto teže disanje nego uobičajeno, a mogu uključivati aktivnosti kao što je na primjer nošenje lakog tereta. Hodanje ne podrazumijeva umjerenu tjelesnu aktivnost. Iako su najveći nivo energetske potrošnje obje grupe starijih žena ostvarile kroz izrazito naporne fizičke aktivnosti, zadovoljavajući nivo energetske potrošnje je ipak otpadao na hodanje.

Poznato je da FA sadržava takođe socijalnu komponentu. Zajednička FA u grupama, pomaže starijim ljudima da se upoznaju sa drugima, te im tako pomaže da prošire svoju društvenu mrežu i poboljšaju svoje zdravlje (Popović \& Bjelica, 2017). Ovo se posebno odnosi na područje slobodnog vremena, koje treba koristiti što više sa ciljem poboljšanja vlastitog zdravlja. Za održavanje kardio-respiratorne funkcije, Bjelica \& Fratrić (2011) preporučuju sljedeće: učestalost od 3-5 dana sedmično; intenzitet od 55-65\% do 90\% maksimalne srčane frekvencije; trajanje od 20-60 minuta neprekidne (kontinuirane) aktivnosti, ili kroz nekoliko intenzivnih serija u trajanju od 10 minuta aktivnosti. Takođe, autori preporučuju fizičke aktivnosti kojima se aktiviraju velike mišićne grupe, kao što su na primjer intenzivni hod, planinarenje, trčanje, džoging, vožnja bicikla, nordijsko skijanje, preskakanje užeta, veslanje, penjanje uz stepenice, plivanje, klizanje i slično. Vjerovatno da je organizam čovjeka u stanju podnijeti produženi fizički rad, kada se aktivira veća mišićna masa.

Iako IPAQ osigurava procjenu metaboličke potrošnje tokom odgovarajućih fizičkih aktivnosti u odnosu na vrijeme koje se provede tokom hodanja, ili prilikom obavljanja aktivnosti umjerenog i visokog intenziteta na poslu, u prevozu, za- 
tim obavljanju poslova u kući i dvorištu, te aktivnostima u slobodnom vremenu, ipak se jasno ne mogu predvidjeti određeni zdravstveni efekti. Takođe, posebno je pitanje kako za svakog pojedinca definisati šta je to mali, srednji i veliki intenzitet (Bjelica, 2015)

Zdravstvene politike trebaju više težiti ka izradi nacionalnih strategija i smjernica, odnosno izgradnji svijesti i načina ponašanja $s$ ciljem fizičke aktivnosti i poboljšanja odnosno održavanja zdravlja osoba starije životne dobi, te stvaranja okruženja koje potiče na fizičku aktivnost tokom cijelog života (Taylor, 2014), što je od velike važnosti za održavanje kvalitete života i upravljanje zdravljem.

Promovisanje fizičkih aktivnosti među osobama starije životne dobi treba biti jedan od prioritetnih zadataka zdravstvene politike u okviru lokalnih zajednica. Pritom je takođe važno osigurati odgovarajuće načine informisanja o zdravstvenom statusu starijih osoba, kako bi se adekvatno mogli odrediti prioriteti djelovanja i planirati adekvatni programi fizičkih aktivnosti.

\section{Acknowledgements}

There are no acknowledgements.

\section{Conflict of Interest}

The authors declare that there are no conflicts of interest.

Received: 10 September 2018| Accepted: 8 October 2018| Published: 29 October 2018

\section{References}

Ainsworth B.E, Haskell, W.L., Whitt, M.C., Irwin, M.L, Swartz, A.M., Strath, S.J., O'Brien WL, Bassett, D.R., Schmitz, K.H., Emplaincourt, P.O., Jacobs, D.R. \& Leon, A.S. (2000). Compendium of physical activities: an update of activity codes and MET intensities. Med Sci Sport Exerc., 32(9), 498-504.

Atlantis, E., Martin, S.A., Haren, M.T., Taylor, A.W., \& Wittert, G.A. (2009) Members of the Florey Adelaide Male Ageing Study. Inverse associations between muscle mass, strength, and the metabolic syndrome. Metabolism. 58(7), 1013-22.

Bjelica, D. (2015). Teorijske osnove tjelesnog i zdravstvenog obrazovanja (2. izdanje). Podgorica - Nikšić: Fakultet za sport i fizičko vaspitanje UCG Crnogorska sportska akademija.

Bjelica, D. \& Fratrić, F. (2011). Sportski trening: teorija, metodika i dijagnostika. Podgorica: Fakultet za sport i fizičko vaspitanje UCG i Crnogorska sportska akademija.

Bjelica, D. (2010). Teorija sportskog treninga. Podgorica: Univerzitet Crne Gore.

Bjelica, B., Hadžic, R., Kezunovic, M., \& Popovic, S. (2014). Aerobni kapaciteti u sportu. Zbornik radova: 12. godišnja međunarodna konferencija "Kondicijska priprema sportaša". Zagreb: Kineziološki fakultet Sveučilišta, Udruga kondicijskih trenera Hrvatske.

Bjelica, D. \& Krivokapić, D. (2010). Teorijske osnove fizičke kulture. Nikšić: Fakultet za sport i fizičko vaspitanje, Univerzitet Crne Gore.
Caspersen, CJ., Powell, KE., \& Christenson, GM. (1985). Physical activity, exercise, and physical fitness: definitions and distinctions for health-related research. Public Health Rep., 100(2), 126-31.

Church, T.S., Blair, S.N. \& Cocreham, S. (2010). Effects of aerobic and resistance training on hemoglobin A1c levels in patients with type 2 diabetes: a randomized controlled trial. JAMA, 304, 2253-62.

Craig, C.L., Marshall, AL, Sjöström, M., Bauman, A.E., Booth, M.L., Ainsworth B.E., Pratt, M., Ekelund, U., Yngve, A., Sallis, J.F. \& Oja, P. (2003). International physical activity questionnaire: 12 -country reliability and validity. Med Sci Sports Exerc., 35(8), 1381-95.

DiPietro, L. (2001). Physical activity in aging: changes in patterns and their relationship to health and function. J Gerontol A Biol Sci Med Sci. 56(2), 13-22.

Jakicic, J.M., Marcus, B.H., Gallagher, K.I., Napolitano, M. \& Lang, W. (2003). Effect of exercise duration and intensity on weight loss in overweight, sedentary women: a randomized trial. JAMA, 290, 1323-30.

Kovacevic, M. (2018). Self-Reported and Objectively Measured Physical Activity of Elderly Mans from Bar. J. Anthr. Sport Phys. Educ., 2(3), 79-83

Knezevic, M. (2018). Self-Reported and Objectively Measured Physical Activity of Elderly Womens From Bar and Podgorica. J. Anthr. Sport Phys. Educ., 2(3), 39-42

Kyu, H.H., Bachman, V.F., Alexander, L.T., Mumford, J.E., Afshin, A., Estep, K, Veerman, J.L., Delwiche, K., lannarone, M.L., Moyer, M.L., Cercy, K., Vos, T., \& Murray, C.J., Forouzanfar, M.H. (2016). Physical activity and risk of breast cancer, colon cancer, diabetes, ischemic heart disease, and ischemic stroke events: systematic review and dose-response meta-analysis for the Global Burden of Disease Study 2013. British Medical Journal, 354,3857

Masanovic, B., Vukotic, M., Bjelica, D. \& Popovic, S. (2018). Describing Physical Activity Profile of Older Montenegrin Males Using the International Physical Activity Questionnaire (IPAQ). Book of Abstracts of the 15th International Scientific Conference on Transformation Process in Sport "Sport Performance". Podgorica: Montenegrin Sports Academy.

Milanović, Z., Pantelić, S., Sporiš, G., Krakan, I. \& Mudronja, L. (2012). Razlike u nivou tjelesne aktivnosti kod muškaraca i žena preko 60 godina starosti. Zbornik radova: 21. ljetna škola kineziologa Republike Hrvatske (163). Poreč: Hrvatski kineziološki savez.

Mitrovic, M. (2018). Self-Reported and Objectively Measured Physical Activity of Males from 50 to 69 Years Old. J. Anthr. Sport Phys. Educ., 2(2), 99-101

Popovic, S., Bjelica, D., Vukotic, M., \& Masanovic, B. (2018). Describing Physical Activity Profile of Older Montenegrin Females Using the International Physical Activity Questionnaire (IPAQ). Book of Abstracts of the 15th International Scientific Conference on Transformation Process in Sport "Sport Performance". Podgorica: Montenegrin Sports Academy.

Popovic, S. \& Bjelica, D. (2017). Eff cts of physical activity on social exclusionamong older people: a literature review. U Conference Book of Abstract of the 8th Conference of HEPA Europe "Modern Approaches to Physical Activity promotion and measurement" (122), Zagreb: HEPA Europe.

Sharkey, B.J. \& Gaskill, S.E. (2008). Vježbanje i zdravlje (6. izdanje). Beograd: Data status.

Taylor, D. (2014). Physical activity is medicine for older adults. Postgrad Med. J. 90(1059), 26-32

Zatsiorsky, V.M. \& Kraemer, W.J. (2009). Nauka i praksa u treningu snage (2. izdanje). Beograd: Data status.

Taylor, D. (2014). Physical activity is medicine for older adults. Postgrad Med. J. 90, 26-32. 